\title{
Matemática, Pensamento Computacional e BNCC: desafios e potencialidades dos projetos de ensino e das tecnologias na formação inicial de professores
}

\author{
Luciana Leal da Silva Barbosa*, Marcus Vinícius Maltempi**
}

\section{Resumo}

Este trabalho traz uma discussão sobre o pensamento computacional na educação matemática acompanhada de um relato de experiência da disciplina Informática e Educação Matemática oferecida em um curso de Licenciatura em Matemática. Esse componente curricular tinha como foco trabalhar o Pensamento Computacional (PC) articulado ao ensino da matemática por meio de atividades mão-na-massa utilizando tecnologias digitais. Tal foco surge da necessidade de atualizar a formação de professores diante das novas diretrizes definidas pela Base Nacional Comum Curricular, que trouxe o Pensamento Computacional como uma das habilidades a serem desenvolvidas nos estudantes da Educação Básica. O objetivo deste texto é, portanto, discutir o PC e refletir sobre as vivências de ensino e aprendizagens desenvolvidas durante essas disciplinas, investigando a seguinte problemática: quais as potencialidades e desafios que surgem nos espaços dedicados à formação inicial de professores quando se propõem trabalhar com práticas de ensino que articulam matemática, PC e competências previstas na Base Nacional Comum Curricular (BNCC)? Os resultados obtidos apontam para diversas possibilidades de se articular esses três elementos ao mesmo tempo em que impõem desafios aos atuais e futuros professores.

Palavras-chave: Educação Básica; Pensamento Computacional; Matemática; Competências; BNCC.

\footnotetext{
* Professora do Instituto Federal de São Paulo - Birigui. Doutoranda no Programa de Pós-graduação em Educação Matemática da Unesp - Rio Claro. Membro do Grupo de Pesquisa em Informática, outras Mídias e Educação Matemática (GPIMEM). Brasil. E-mail: luciana.leal@ifsp.edu.br

* Professor do Departamento de Estatística, Matemática Aplicada e Computação e do Programa de Pós Graduação em Educação Matemática. Membro do Grupo de Pesquisa em Informática, outras Mídias e Educação Matemática (GPIMEM). Apoiado pela FAPESP (Processo 2018/14053-2) e CNPq (Processo 308563/2019-0). Rio Claro, SP, Brasil. E-mail: marcus.maltempi@unesp.br
} 


\section{Introdução}

A Base Nacional Comum Curricular publicada em 2018 fundamenta toda a Educação Básica no conceito de competências, incluindo também de forma expressa as tecnologias digitais como elementos fundamentais no ecossistema escolar (BRASIL, 2018). Além disso, introduz um elemento relativamente novo e desconhecido, que vem sendo enfatizado no contexto educacional mundial apenas a partir de 2006: o Pensamento Computacional (PC). O contexto em que este termo é inserido no Ensino Fundamental sugere que o PC consiste numa competência e/ou habilidade a ser desenvolvida durante processos de ensino de conteúdos da matemática. Relacionado a estes conteúdos, o texto afirma que ao se trabalhar determinadas estratégias de aprendizagem da matemática como resolução de problemas, investigação e modelagem matemática, cria-se um ambiente rico para se desenvolver competências relacionadas ao letramento matemático e também ao pensamento computacional. Da mesma forma, outro trecho afirma que aprender Álgebra contribui para o desenvolvimento do PC nos alunos. Já no Ensino Médio, o PC é retomado como um dos elementos cuja aprendizagem deve ser iniciada no nível anterior, mas ampliado e consolidado nesse nível, buscando ampliar "o leque de recursos para resolver problemas mais complexos, que exijam maior reflexão e abstração" (BRASIL, 2018). Sua importância é ainda reforçada ao ser incluído como uma das dimensões educacionais que contemplam conhecimentos, atitudes e valores a serem desenvolvidos durante os três anos desse ciclo.

Posto desta forma, entende-se que, assim como as competências gerais deverão ser desenvolvidas durante o processo de ensino das aprendizagens essenciais (conhecimentos, habilidades, atitudes, valores), o mesmo se aplica ao PC, desde que este também seja concebido de forma articulada a tais aprendizagens. Assim, cabe ao professor, em especial ao professor de matemática, não apenas ensinar o conhecimento matemático (conteúdo), mas também, desenvolver nos seus alunos as competências gerais e específicas e o PC. Dentro deste contexto, surge o seguinte desafio: como os professores irão desenvolver processos de ensino e aprendizagem capazes de trabalhar de forma articulada conteúdos da matemática, pensamento computacional e competências da BNCC?

Tal questão torna-se urgente a partir da publicação do texto da Base, devendo agora passar do plano normativo para o plano prático. Desta forma, este trabalho 
discute essa questão e apresenta um relato de experiência de ensino vivenciada na disciplina Informática na Educação Matemática (IEM) num curso de Licenciatura em Matemática. O objetivo do curso foi trabalhar com os licenciandos conceitos, pesquisas e práticas que articulam Pensamento Computacional, Matemática, e Competências da BNCC através de projetos e atividades mão-na-massa com o uso de tecnologias digitais. A partir desta experiência, discutimos a seguinte problemática: quais as potencialidades e desafios que surgem nos espaços dedicados à formação de professores quando se propõem trabalhar com práticas de ensino que articulam matemática, pensamento computacional e competências previstas na BNCC?

A disciplina IEM é um componente oferecido no sétimo semestre do curso de Licenciatura em Matemática em uma universidade pública no estado de São Paulo. Os resultados obtidos pelos autores e docentes destas disciplinas apontam para diversos desafios e potencialidades quando se propõem trabalhar o ensino de matemática articulado ao PC e às competências da BNCC num espaço de formação inicial de professores.

\section{Concepções sobre o Pensamento Computacional}

A origem do Pensamento Computacional pode estar relacionada aos trabalhos de Papert (1980), um dos criadores da linguagem Logo, que concebe o computador como um recurso que estende as capacidades da mente humana para "forjar ideias", permitindo que as pessoas analisem, modelem e resolvam problemas com mais eficiência e fazendo uso de mais e melhores recursos. Mas foi a partir do artigo de Wing (2006) que o termo despertou o interesse da comunidade de educadores e de cientistas da computação. Nesta publicação, ela define o PC como uma abordagem para resolução de problemas, projetar sistemas e compreender o comportamento humano que se baseia em conceitos da ciência da computação, atribuindo ao PC a mesma importância de habilidades básicas como ler, escrever e calcular (WING, 2006). Já na literacia computacional de Vee (2013), o termo PC está fortemente relacionado à programação de computadores, a qual afirma que a literacia computacional consiste na habilidade de dividir um problema complexo em subproblemas menores, que devem ser representados por meio de uma tecnologia que pode ser lida por uma máquina. 
Apesar de não existir consenso sobre uma definição única para o PC, seus defensores concordam em afirmar que a Educação Básica pode e deve usufruir de diversos benefícios quando articulada a ele. Neste sentido, surgiram diversas iniciativas ao redor do mundo na tentativa de construir uma definição mais clara e próxima da prática do docente. A Computer Science Teachers Association (CSTA, 2011) define o PC em termos dos seguintes conceitos: formulação de problemas, organização e análise lógica de dados, abstração, simulação, pensamento algorítmico, avaliação de eficiência e corretude e generalização. Já a Computing at School (2015) relaciona ao PC as habilidades de raciocínio lógico, pensamento algorítmico, decomposição, generalização, reconhecimento de padrões, abstração, representação e avaliação. Citamos ainda a concepção da International Society for Technology in Education (ISTE, 2016) sobre o PC: coleta, análise e representação de dados, decomposição, abstração, algoritmos, automação, teste, paralelização e simulação. No Brasil, duas instituições têm dedicado esforços no sentido de contribuir para a inclusão de temas da ciência da computação no currículo da Educação Básica. A primeira delas é a Sociedade Brasileira de Computação ${ }^{1}$ (SBC) através da elaboração de um documento com diretrizes para o ensino de computação na Educação Básica, no qual afirma que "o empoderamento dos conceitos fundamentais da Computação permitirá que estudantes compreendam de forma mais completa o mundo e tenham, consequentemente, maior autonomia, flexibilidade, resiliência, pró-atividade e criatividade" (SBC, 2019, p. 1). O documento organiza o conhecimento em computação em três eixos: Cultura Digital, Mundo Digital e Pensamento Computacional. Sobre este último, atribui-se o seguinte conceito: "capacidade de compreender, definir, modelar, comparar, solucionar, automatizar e analisar problemas (e soluções) de forma metódica e sistemática, através da construção de algoritmos" (SBC, 2019, p.5). Em sua definição, o PC inclui três habilidades ou processos cognitivos: abstração, análise e automação.

Sobre o PC, a SBC sugere a inclusão destas habilidades ao conjunto de habilidades e competências estimuladas e desenvolvidas nos estudantes da Educação Básica, enfatizando sobretudo a construção de algoritmos como um produto resultante do processo de formulação e resolução de problemas, pois é considerado "presente em todas as áreas e está intrinsecamente ligado à resolução de problemas” (SBC, 2019, p. 5), sendo concebido como uma descrição do processo de um determinado problema. Neste sentido, compreendemos a relação entre estas três habilidades da seguinte 
forma: a abstração e análise devem ser utilizadas com o objetivo final de modelar e construir a solução de um problema através de um algoritmo, compreendido como uma representação da solução e que poderá ser escrito numa linguagem de programação e executado por uma máquina (automação). A Figura 1 ilustra a relação entre cada eixo proposto pela SBC, bem como as três habilidades relacionadas ao Pensamento Computacional.

Figura 1 - Conhecimentos da Ciência da Computação divididos em três eixos Básicos: Cultura Digital, Mundo Digital e Pensamento Computacional

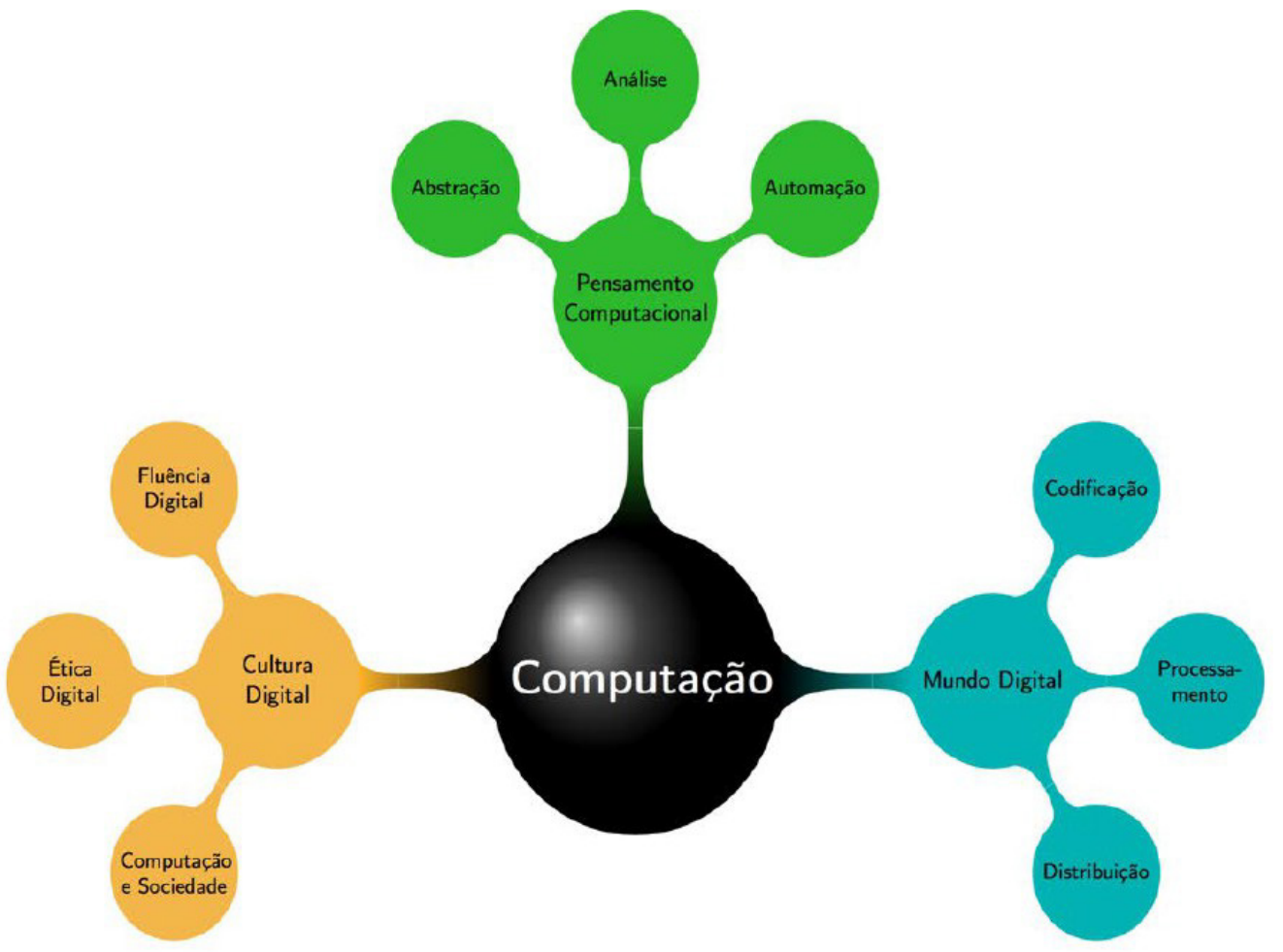

Fonte: SBC, 2019, p. 3.

Da mesma forma, o CIEB - Centro de Inovação para a Educação Brasileira ${ }^{2}$ -, dentre outras iniciativas, elaborou e publicou um currículo de referência em tecnologia e computação para a Educação Infantil e Ensino Fundamental como uma proposta curricular complementar à BNCC que enfatiza o uso das tecnologias durante os processos de ensino e de aprendizagem. A ideia é apoiar as equipes pedagógicas das escolas "quanto às aprendizagens essenciais em relação às tecnologias 
e as premissas da computação, destacando o que é necessário para se alcançar os objetivos de cada ano escolar" (CIEB, 2018, p. 15).

Neste currículo, os conteúdos relacionados à tecnologia e computação podem ser trabalhados de forma transversal ou em um componente curricular dedicado à computação, e estão organizados em três eixos estruturantes: Cultura Digital, Tecnologia Digital e Pensamento Computacional, sendo que este último "compreende sistematizar, representar, analisar e resolver problemas" (CIEB, 2018, p. 19), ou seja, está relacionado à capacidade de resolução de problemas fazendo uso de conhecimentos de práticas da computação. Ele é abordado em termos de quatro conceitos: abstração, algoritmos, decomposição e reconhecimento de padrões.

Analisando-se as diferentes abordagens e definições atribuídas ao PC, percebe-se que vários dos conceitos a ele relacionados se repetem, e no que se refere às propostas brasileiras, o PC contempla uma quantidade menor de conceitos. Além disso, todos possuem ampla aplicação no domínio da ciência da computação, e também em outros domínios. A falta de consenso sobre um conjunto único de habilidades relacionadas ao PC ou sobre uma definição mais precisa aumentam os desafios para sua compreensão e inserção em práticas pedagógicas, o que nos faz refletir sobre o seguinte questionamento: como colocar o PC em prática numa sala de aula com o objetivo de se ensinar e aprender conceitos matemáticos e desenvolver as competências da BNCC? Diversas pesquisas sugerem possibilidades que fazem frente a esta pergunta. Algumas delas serão apresentadas e discutidas na próxima seção.

\section{A Educação Matemática e o Pensamento Computacional}

A história da reforma educacional da matemática está repleta de inovações concebidas com entusiasmo, mas sem transferência significativa para a sala de aula (GADANIDIS, 2015). Um impedimento estrutural para reformar é o padrão curricular que identifica e limita o que os alunos podem e devem aprender e fazer. Gadanidis (2015) define dois principais impedimentos para uma reforma mais ampla e profunda na educação matemática: a estrutura curricular e a crença de que ideias matemáticas mais complexas e abstratas não podem ser compreendidas por crianças. Sobre o currículo, afirma que sua estrutura estanque e rígida, que divide grandes ideias matemáticas encaixando-as em níveis específicos de ensino, tem como consequência a perda de conexões e relacionamentos significativos entre 
os conceitos, assim como ideias matemáticas consideradas mais complexas são tomadas como acima do alcance das crianças. Por outro lado, existe a crença de que o sistema cognitivo das crianças pequenas não está pronto para compreender ideias matemáticas mais complexas e abstratas. Estes dois impedimentos trabalham juntos para diminuir o potencial matemático das crianças, resultando numa educação matemática que enfatiza aquilo que as crianças não podem fazer.

O PC tem sido considerado em diversas pesquisas na educação matemática como um aliado no processo de mudança na forma como os conceitos matemáticos são ensinados. Além disso, pesquisas indicam a importância de se desenvolver o PC já na Educação Básica, comparando-o a habilidades básicas como ler, escrever e calcular (WING, 2006). Seus defensores, tanto na área da educação quanto na ciência da computação, sugerem a inclusão de um currículo voltado ao estudo da ciência da computação na Educação Básica.

Gadanidis (2015) sugere o uso da programação como recurso para realizar uma ampla e profunda reforma na educação matemática, e como estratégia para ensinar conceitos matemáticos e ideias mais complexas a crianças pequenas, construindo assim um ambiente de modelagem e resolução de problemas. Em Gadanidis et al. (2017), os autores apresentam um estudo de caso que investiga as aulas de matemática de uma turma do primeiro ano da Educação Básica, com conteúdos que incluem conceitos de geometria e probabilidade. A intenção é verificar o potencial do PC na educação matemática para engajar crianças pequenas em ideias e relacionamentos matemáticos mais complexos, para além daqueles previstos no currículo obrigatório para o mesmo nível de ensino. O desafio é migrar "do que é" para "o que poderia ser" ou "o que deveria ser" o saber e fazer matemático, explorando as possibilidades advindas da articulação entre o PC e a educação matemática através da codificação e construção de algoritmos.

Para tanto, em seu trabalho o PC é concebido sob três perspectivas: 1) através de atividades de codificação ou programação; 2) construção e programação de objetos digitais tangíveis, e; 3) construção de algoritmos. Além disso, definem o conceito de PC em relação a sete possibilidades pedagógicas: 1) piso baixo, teto alto; 2) abstração e automação; 3) modelagem dinâmica; 4) sentimento tangível; 5) surpresa conceitual; 6) paredes largas, e; 7) Controle. Pretendem assim abrir espaço para discussão, reflexão, crítica e, por que não, reconceituação desta abordagem de PC articulado à educação matemática (GADANIDIS et al., 2017). 
Resnick (2018) vai além da necessidade de ensinar e aprender os conteúdos previstos no currículo. A ela, adiciona a importância e, portanto, necessidade de se incluir uma habilidade indispensável para a sociedade atual: a criatividade. Ele define o termo Pensamento Criativo e discute duas tecnologias desenvolvidas sob sua liderança cujo objetivo é estimular o pensamento criativo das crianças, sugerindo seu uso nas escolas para apoiar metodologias de ensino não tradicionais capazes de inserir os alunos como protagonistas de seu aprendizado, como construtores do seu próprio conhecimento com autonomia e criatividade. São elas o Scratch e Crickets. A primeira, uma plataforma para programação de jogos e animações. A segunda, um conjunto de dispositivos de hardware e um ambiente de programação. Tais tecnologias suportam o que o autor chama de pensamento criativo em espiral (RESNICK, 2018).

O currículo do CIEB pode contribuir para articulação entre PC e matemática por meio das Práticas, que consistem em uma ou mais sugestões de práticas pedagógicas para cada uma das 147 habilidades computacionais definidas no documento. É por meio delas que se estabelece um alinhamento possível entre as habilidades do currículo do CIEB e as habilidades da BNCC, contribuindo para definir a relação entre os conceitos de computação e os conceitos das demais áreas do conhecimento (CIEB, 2018). A Tabela 1 apresenta um exemplo da relação entre uma habilidade do PC e uma habilidade matemática da BNCC para o segundo ano do EF, por meio da qual o professor pode trabalhar, concomitantemente, a habilidade em computação e a habilidade matemática através de experiências práticas envolvendo a construção de algoritmos que incluem estruturas de repetição. A própria ideia da multiplicação envolvendo múltiplas adições de parcelas iguais pode ser explorada na construção de algoritmos que resolvem cálculos de multiplicações em diferentes contextos. A prática cumpre assim seu objetivo de alinhar o currículo de computação à BNCC.

Tabela 1 - Relação entre habilidade em computação e habilidade da BNCC

\begin{tabular}{|l|l|l}
\hline $\begin{array}{l}\text { Habilidade do currículo de } \\
\text { Tecnologia e Computação }\end{array}$ & \multicolumn{1}{|c|}{ Prática Sugerida } & \multicolumn{1}{c}{ Habilidade da BNCC } \\
\hline & $\begin{array}{l}\text { Criar algoritmos utilizando re- } \\
\text { petições - por exemplo, crian- } \\
\text { do programas simples que }\end{array}$ & $\begin{array}{l}\text { F02MA07: Resolver e elaborar pro- } \\
\text { blemas de multiplicação (por 2, 3, 4 e } \\
\text { 5) com a ideia de adição de parcelas }\end{array}$ \\
$\begin{array}{l}\text { PC02AL01: Compreender } \\
\text { O uso de repetição com } \\
\text { número fixo de iterações }\end{array}$ & $\begin{array}{l}\text { utilizem pelo menos uma itera- } \\
\text { ção com 4 repetições, encon- } \\
\text { trando e corrigindo seus erros } \\
\text { e ajudando os demais colegas }\end{array}$ & $\begin{array}{l}\text { mas de registro pessoais, utilizando } \\
\text { ou não suporte de imagens ou mate- } \\
\text { rial manipulável }\end{array}$ \\
\hline
\end{tabular}

Fonte: Autores (2020) com base no exposto em (CIEB, 2019, p.43). 
Diante destas possibilidades de articular matemática e PC, pretendemos agora lançar um olhar para pesquisas que investigam formas de se integrar o PC ao currículo da Educação Básica, na tentativa de vislumbrar possibilidades de cumprir o disposto pela BNCC. Tal relação entre PC e currículo se mostra um importante objeto de reflexão neste texto se considerarmos a realidade da Educação Básica brasileira, pautada sobretudo na construção e cumprimento dos rígidos currículos escolares.

\section{O Pensamento Computacional e o currículo da Educação Básica}

O PC foi inserido explicitamente no texto da BNCC. E como este consiste num documento normativo, espera-se que seja observado durante a construção dos currículos pelos diversos sistemas de ensino. Neste cenário, pergunta-se: quais são os desafios que surgem ao se propor ações voltadas para a compreensão e inclusão do PC nos currículos? Uma vez incluído nos currículos, como colocá-lo em prática?

Estas perguntas nos levam a refletir sobre a conceituação clara e objetiva do termo PC, seu uso na educação, sua inserção no currículo, sua prática em sala de aula, e formação inicial e continuada de professores.

O processo para a inclusão do PC nos currículos da Educação Básica se iniciou em outros países e tem sido objeto de diversas pesquisas. Nas últimas décadas têm crescido o número de discussões e publicações acerca da introdução de conteúdos da ciência da computação nos currículos escolares. Mannila et al. (2014) apresentam um relatório sobre o estado do PC em diversos países na Europa e também nos EUA. Seu objetivo é contribuir com professores, formadores de professores e gestores da educação sobre como e quando instituir o PC nas instituições de ensino. O relatório aborda os seguintes temas: definição do conceito de PC; o estado atual do PC nos noves primeiros anos da educação básica (K-9) na Europa e nos EUA; iniciativas de implementação do PC na educação informal nos mesmos países.

De acordo com seus autores, as principais contribuições do trabalho são: uma pesquisa de campo realizada com professores a fim de determinar se eles já desenvolvem alguma atividade relacionada ao PC em suas aulas; sugestão de atividades que incluem aspectos relacionados ao PC em diferentes assuntos; apresentação de uma forma de integrar o PC na formação dos professores; discussão da questão dos repositórios; sugestões de questões de pesquisa em PC. Os argumentos dos auto- 
res a favor da introdução do PC no currículo da educação formal são explicitados no texto: a oportunidade de oferta da ciência da computação para todos; temas da ciência da computação desenvolvem habilidades do PC e pensamento crítico nos alunos; permitir que o aluno entenda como as tecnologias são criadas e não apenas usadas; este conhecimento é fundamental para formar pessoas capazes de agir no século XXI. Logo, o artigo não questiona se o PC deve ou não ser integrado ao currículo. Ao contrário, certos de que o PC deve ser integrado ao currículo, levanta os seguintes questionamentos: O que deve ser ensinado? Deve-se integrar este conteúdo a outras disciplinas ou criar uma disciplina própria? Como os educadores aprenderão a ensiná-lo? Qual material deve ser usado? Responder estas questões implica definir um caminho a ser percorrido com o objetivo de incluir o PC no currículo (MANNILA et. al., 2014).

Almeida e Valente (2019) apresentaram um estudo procurando entender as políticas e uso das Tecnologias Digitais de Informação e Comunicação (TDIC) na educação de alguns países - Estônia, Portugal, Espanha e Finlândia, bem como analisar como essas políticas orientam a realização de práticas pedagógicas que exploram o conceito de programação com foco no desenvolvimento do pensamento lógico e computacional. Os autores trazem para o debate o que se entende por pensamento computacional e o como tem se dado sua inserção na Educação Básica, indicando alguns exemplos de atividades que tem o potencial de explorar o PC.

Segundo os autores, vários países têm buscado alterar seu currículo no intuito de incluir a programação ou conceitos da ciência de computação, principalmente nos primeiros anos da Educação Básica. Em relação os países investigados, percebe-se que cada um adota uma estratégia diferente para a construção de suas políticas de inclusão das TDIC na educação: programação fora da sala de aula (EUA); inserção de disciplinas no currículo que usam tecnologias para explorar temas relativos ao letramento digital (Lituânia, Holanda, Suécia, Portugal, Grécia, Irlanda, Bulgária); inclusão de disciplinas no currículo que exploram conceitos do pensamento computacional (Inglaterra); exploração dos conceitos do PC de maneira transversal (Itália). Desta forma, eles classificam estas estratégias de implantação em três grandes categorias: i) atividades de ciência da computação (programação fora da sala de aula, e disciplinas no currículo sobre computer literacy); ii) disciplinas curriculares com foco no pensamento computacional através de jogos e robótica, e; iii) pensa- 
mento computacional de maneira transversal, por meio de atividades que usam as tecnologias em diferentes disciplinas do currículo (ALMEIDA e VALENTE, 2019).

Em meio aos esforços práticos na tentativa de implementar o PC na Educação Básica, pesquisas também apontam os desafios e as muitas dúvidas que surgem. $\mathrm{O}$ trabalho de Dennning (2017) tenta responder a vários questionamentos de professores que tentam trabalhar com o PC em suas práticas de ensino. Ao autor foram solicitados esclarecimentos sobre três principais questões: O que é o PC? Como avaliar as habilidades computacionais dos estudantes? O PC é bom para todos? $\mathrm{Na}$ tentativa de respondê-las, ele pretende esclarecer o conceito ainda não consensual do PC e para quem o PC é bom, sugerindo também um método avaliativo.

Em seu discurso, Denning (2017) critica principalmente a imprecisão das definições dadas atualmente ao PC e as afirmações não fundamentadas promovidas por entusiastas, as quais minam os esforços organizados na tentativa de divulgar a ciência da computação, enraizam expectativas que não poderão ser satisfeitas, e deixam os professores numa situação desconfortável de não saber o que exatamente vão ensinar e como irão avaliar se seus objetivos foram alcançados. Almeida e Valente (2019) também discutem aspectos relacionados à avaliação dos estudantes que "aprendem" o pensamento computacional indicando estratégias e metodologias diversificadas que tentam identificar se os sujeitos desses estudos estão conscientes e desenvolvendo os comportamentos ou habilidades contempladas nas atividades práticas e alvos da investigação.

Outras pesquisas vislumbradas voltam-se para questões relacionadas à formação inicial dos professores. Yadav, Stephenson e Hong (2017) afirmam a necessidade de se incorporar ao currículo dos cursos de formação inicial de professores o conhecimento sobre PC e suas habilidades. A fim de tornar a proposta mais praticável, os autores apresentam exemplos de como os educadores de professores podem trabalhar com o PC nas diferentes disciplinas de uma licenciatura ou em cursos livres, e de como os professores atuantes nas diversas áreas do conhecimento podem incorporar o PC em atividades desenvolvidas na sala de aula.

Apesar de concordarem com a importância de se introduzir o PC nos currículos da Educação Básica, discutem que o sucesso destas iniciativas depende, em muito, das ações dos educadores de professores, os quais precisam preparar os futuros professores para conhecer o PC durante sua formação inicial, fornecendo o conteúdo, a pedagogia e as metodologias necessárias para incorporar o PC nos currículos 
disciplinares e práticas de ensino. Esta é a afirmação chave que norteia as ideias apresentadas, pois a crença dos autores está na oportunidade de preparar o trabalho dos futuros professores sobre PC durante a sua formação inicial.

Sejam em áreas específicas ou polivalentes, Yadav, Stephenson e Hong (2017) reconhecem que pouco se sabe sobre como articular o conhecimento relativo ao PC ao conhecimento específico de cada área do conhecimento, ou mesmo como engajar os futuros professores no estudo sobre ciência da computação e PC. Eles ainda relatam a escassez de cursos específicos para a formação de professores em ciência da computação. Sobre estes cursos, vale aqui abrir um parênteses para compreender como eles são organizados e ofertados pelas instituições brasileiras.

O catálogo de cursos superiores do Ministério da Educação inclui o curso de Licenciatura em Computação. A Resolução nº 5, de 16 de novembro de 2016 (BRASIL, 2016), institui as Diretrizes Curriculares Nacionais para os cursos de graduação na área da Computação, o que também inclui o curso de Licenciatura em Computação. O parágrafo $5^{\mathrm{o}}$ deste documento define o perfil do egresso para o curso de Licenciatura em Computação, estabelecendo que além de atenderem ao disposto sobre o perfil dos egressos dos cursos de Formação de Professores para a Educação Básica, também devem desenvolver diversas outras habilidades, das quais enfatizamos:

- Sólida formação em ciência da computação, visando o ensino desta ciência na educação básica.

- Serem capazes de fazerem uso da interdisciplinaridade;

- Desenvolverem capacidade de atuar como docentes, estimulando a atitude investigativa com visão crítica e reflexiva.

Tais características foram destacadas por estarem relacionadas às habilidades já definidas para o PC. Desta forma, além de serem competentes para atuarem nas áreas relacionadas à docência na Educação Básica, os futuros professores em Licenciatura em computação também devem desenvolver diversas habilidades relacionadas à ciência da computação e, consequentemente, ao PC. Isto posto, seriam estes egressos os melhores candidatos para atuarem como formadores de professores nas disciplinas de computação durante a formação inicial dos licenciandos? Independente da resposta, não podemos excluir da lista de candidatos os bacharéis da ciência da computação. Entretanto, sobre estes últimos, vale refletir: as competências adquiridas num curso de bacharel os tornam hábeis para articular o PC aos conhecimentos de conteúdo, pedagogia e metodologias de ensino, como sugerido 
em Yadav, Stephenson e Hong (2017)? Esta questão ganha ainda mais relevância a partir da publicação de novas diretrizes para os cursos de formação inicial de professores, a Base Nacional Comum para a formação inicial de professores da Educação Básica (BNC - Formação)

Publicada em fevereiro de 2020, a Base Comum para os cursos de licenciatura surgiu com o objetivo de alinhar a formação inicial docente às novas demandas trazidas pela BNCC. Este documento tem como objetivo regulamentar os projetos de curso das licenciaturas, que precisam a partir de então incluir um conjunto de competências gerais, específicas e habilidades docentes com o objetivo de ofertar uma formação inicial que capacite o futuro professor a pôr em prática os pressupostos pedagógicos definidos pela BNCC. Tal intenção está posta de forma clara no texto, fazendo parte do rol de habilidades docentes, os quais precisam

Compreender e conectar os saberes sobre a estrutura disciplinar e a BNCC, utilizando este conhecimento para identificar como as dez competências da Base podem ser desenvolvidas na prática, a partir das competências e conhecimentos específicos de sua área de ensino e etapa de atuação, e a inter-relação da área com os demais componentes curriculares (BRASIL, 2020, p. 15).

Desta forma, os cursos de licenciatura devem garantir uma formação voltada aos conteúdos específicos de sua área, aos conhecimentos didático-pedagógicos, e a uma prática voltada ao desenvolvimento das habilidades e competências nos estudantes da Educação Básica. O conjunto de competências docente da BNC também contempla as tecnologias enfatizando a busca de soluções tecnológicas, o uso da linguagem digital como forma de expressão e compartilhamento de ideias e experiências, a compreensão, utilização e criação de tecnologias digitais de forma crítica, significativa e ética, o uso como recurso pedagógico, ferramenta de formação, produção de conhecimento e resolução de problemas e para potencializar as aprendizagens de seus futuros alunos.

No que diz respeito ao pensamento computacional, a BNC-Formação afirma que os licenciandos devem desenvolver uma "compreensão básica dos fenômenos digitais e do pensamento computacional, bem como de suas implicações nos processos de ensino-aprendizagem na contemporaneidade" (BRASIL, 2020, p. 6). Esta é a única menção ao PC neste documento, o qual é previsto como integrante da temática didática e seus fundamentos do Grupo I que congrega os temas relativos aos conhecimentos científicos, educacionais e pedagógicos que fundamentam a educação. 
Diante deste cenário posto pela BNC - Formação, diversas questões surgem provocando reflexões sobre a inserção do PC nos currículos das licenciaturas: Como os educadores de professores podem desenvolver estratégias para ensinar os constructos do PC aos futuros professores? Como o PC será contextualizado nas diversas áreas do conhecimento? Como desenvolver a base de conhecimento dos futuros professores, tornando-os capazes de preparar para seus futuros alunos experiências relevantes, significativas e engajadas ao PC?

Yadav, Stephenson e Hong (2017) sugerem respostas a estas perguntas, indicando uma sequência de trabalho que parece óbvia: os educadores de professores precisam primeiro desenvolver o $\mathrm{PC}$ nos licenciandos, e depois prepará-los para serem capazes de desenvolver o mesmo PC nos alunos da Educação Básica. Além disso, os futuros professores precisam aprender a relacionar o $\mathrm{PC}$ aos conhecimentos específicos da sua área de formação. De fato, mas como?

As experiências relatadas neste trabalho apontam para as dificuldades inerentes a este processo de formação inicial, indicando que não basta aos futuros professores compreenderem o conceito do PC, mas antes precisam experimentar na prática as habilidades relacionadas a ele, ao mesmo tempo em que tem a oportunidade de desenvolver seu próprio PC. Além disso, eles precisam enxergar como articular o PC à matemática de forma prática, construindo e praticando atividades de ensino para este fim. Esta estratégia foi adotada na disciplina e será relatada na seção seguinte.

\section{Procedimentos Metodológicos da disciplina Informática na Educação Matemática}

O componente curricular Informática na Educação Matemática (IEM), no curso de Licenciatura em Matemática teve como objetivo proporcionar um espaço de formação para investigar, construir, discutir e refletir sobre possibilidades de se ensinar e aprender matemática, desenvolver o pensamento computacional e as competências da BNCC de forma articulada e através do uso das tecnologias digitais, capacitando-os a articular seu uso num processo de ensino e aprendizagem que inclui conteúdo (currículo), metodologia e recursos.

A disciplina foi ministrada no primeiro semestre de 2019. Nesta oportunidade, a docente incluiu a BNCC como pano de fundo para o estudo dos demais temas durante o curso. Ao analisarmos (professora e alunos) as competências gerais e específicas 
da área Matemática previstas na BNCC, iniciou-se uma discussão e reflexão sobre como um professor de matemática poderia desenvolvê-las durante suas aulas. As seguintes questões nortearam a discussão: as competências definidas pela BNCC são consideradas objetos de ensino nas escolas atualmente? São tão importantes quanto o conteúdo a ser ensinado? Como um professor pode "ensiná-las" a seus alunos? As aulas de matemática, da forma como são tradicionalmente ministradas, têm o potencial de desenvolvê-las? Como trabalhá-las em sala de aula ao mesmo tempo em que se ensina o conteúdo de matemática? Por que elas são tão importantes para a sociedade atual?

Para fins de ilustração, cita-se abaixo duas competências: a primeira geral, e a segunda específica da área de Matemática:

Exercitar a curiosidade intelectual [...] recorrer à investigação, a reflexão, a análise crítica, a imaginação e a criatividade, para investigar causas, elaborar e testar hipóteses, formular e resolver problemas e criar soluções (inclusive tecnológicas) com base nos conhecimentos das diferentes áreas (BRASIL, 2018, pg. 11);

Utilizar processos e ferramentas matemáticas, inclusive tecnologias digitais disponíveis, para modelar e resolver problemas cotidianos, sociais e de outras áreas de conhecimento, validando estratégias e resultados (BRASIL, 2018, pg. 269).

Analisando-se esses excertos, percebe-se diversas dificuldades relacionadas a como desenvolver tais competências através das aulas tradicionais de matemática. Durante os encontros com os licenciandos, uma das questões que nos inquietou foi: como exercitar a curiosidade intelectual e fazer uso de uma estratégia científica para formular e resolver problemas (inclusive tecnológicos) numa aula tradicional de matemática que usa giz, lousa, apostilas e que se preocupa em definir e formular conceitos, e memorizar e executar algoritmos para resolução de exercícios, com o único objetivo de permitir que alunos obtenham conceitos satisfatórios nas avaliações? Reconhece-se os esforços e algumas poucas iniciativas de escolas e professores na tentativa de mudar este paradigma de aula. No entanto, os sistemas de ensino, em sua maioria, são tradicionais e voltados para a transferência de conteúdos, memorização de algoritmos e métodos de resolução de problemas, e um sistema de avaliação estanque e quantitativo.

A conclusão dos licenciandos foi: nossos alunos não são preparados para utilizar o conhecimento assimilado para formular e resolver problemas através de métodos sistemáticos, exercitando sua criatividade durante a construção de suas soluções. 
Soma-se a isto, a falta de recursos pedagógicos, principalmente no que se refere às tecnologias digitais, nas escolas públicas. Diante desta realidade, como os futuros professores podem romper com o paradigma de aula tradicional para construir ambientes de ensino e aprendizagem de matemática que sejam capazes de alcançar os objetivos previstos no texto da BNCC?

Esta questão serviu como motivação para a busca e investigação dos discentes. A proposta da primeira autora e professora foi utilizar o PC como elemento articulador para o ensino do conteúdo matemático e desenvolvimento das competências gerais e específicas de matemática. Desta forma, o PC foi incluído como um dos tópicos a serem estudados nesta disciplina.

Considerando a dificuldade de se obter uma definição única na literatura, e na tentativa de aproximá-lo da prática do docente em sala de aula, o PC foi concebido sob a forma de habilidades a serem desenvolvidas nos alunos, com a meta de contribuir para se alcançar os objetivos definidos pela BNCC. Após aulas de estudo, investigação e discussão sobre o tema, apresentou-se uma proposta que envolvia o planejamento e a prática de atividades de ensino. Este trabalho consistiu em se construir um projeto didático com o objetivo de ensinar um conteúdo específico da matemática, articulando-o ao PC definido em termos de algumas de suas habilidades, investigando assim suas contribuições para a aprendizagem do conteúdo e para 0 desenvolvimento das competências previstas no texto da base.

$\mathrm{O}$ conceito de $\mathrm{PC}$ e suas habilidades relacionadas foi ilustrado por meio de atividades de programação, de tal forma que os licenciandos pudessem compreender e experimentar como as habilidades poderiam ser desenvolvidas a partir da exploração e manipulação de atividades mão-na-massa. Para tanto, apresentou-se a plataforma de programação Scratch $^{3}$ como um recurso viável para a construção de atividades por professores e sua manipulação e programação pelos alunos.

Como exemplo, foi apresentado o jogo Balança das Equações programado pela primeira autora durante a disciplina Pensamento Computacional na Educação Matemática, ofertada pelo segundo autor no Programa de Pós-Graduação em Educação Matemática da Unesp de Rio Claro. Este jogo foi desenvolvido com o objetivo de trabalhar os conceitos iniciais de equações do primeiro grau junto a uma turma de reforço do sétimo ano do ensino fundamental ao mesmo tempo em que se possibilitava o desenvolvimento de habilidades relacionadas ao PC (BARBOSA; MALTEMPI, 2019). Essa experiência foi compartilhada e discutida com a turma de 
licenciandos. Ao apresentar e manipular o software, os futuros professores tiveram a oportunidade de experimentar o ambiente de aprendizagem construído, analisar suas caraterísticas, seu código, e assim compreender como o conteúdo matemático e as habilidades do PC poderiam ser trabalhadas em conjunto.

O jogo foi construído para permitir que os alunos manipulassem uma balança de pratos, colocando e retirando maçãs de seus pratos, a fim de investigar o comportamento da balança. A fase de exploração realizada com autonomia envolvia a manipulação das maçãs sobre os pratos e a observação do comportamento da balança ao se retirar e colocar maçãs sobre os pratos, elaborar conjecturas para os eventos observados, e validar ou rejeitar suas hipóteses. A exploração do jogo e mediação do professor permitiu que as crianças compreendessem o princípio do equilíbrio da balança através da experiência proporcionada pela interação e dinamismo do jogo, o que permitiu a definição de uma analogia entre o princípio do equilíbrio e a igualdade de uma equação (BARBOSA; MALTEMPI, 2019). A Figura 2 ilustra uma das telas do jogo.

Figura 2 - Jogo Balança das Equações desenvolvido no Scratch para o ensino e aprendizagem dos conceitos iniciais sobre equações do primeiro grau

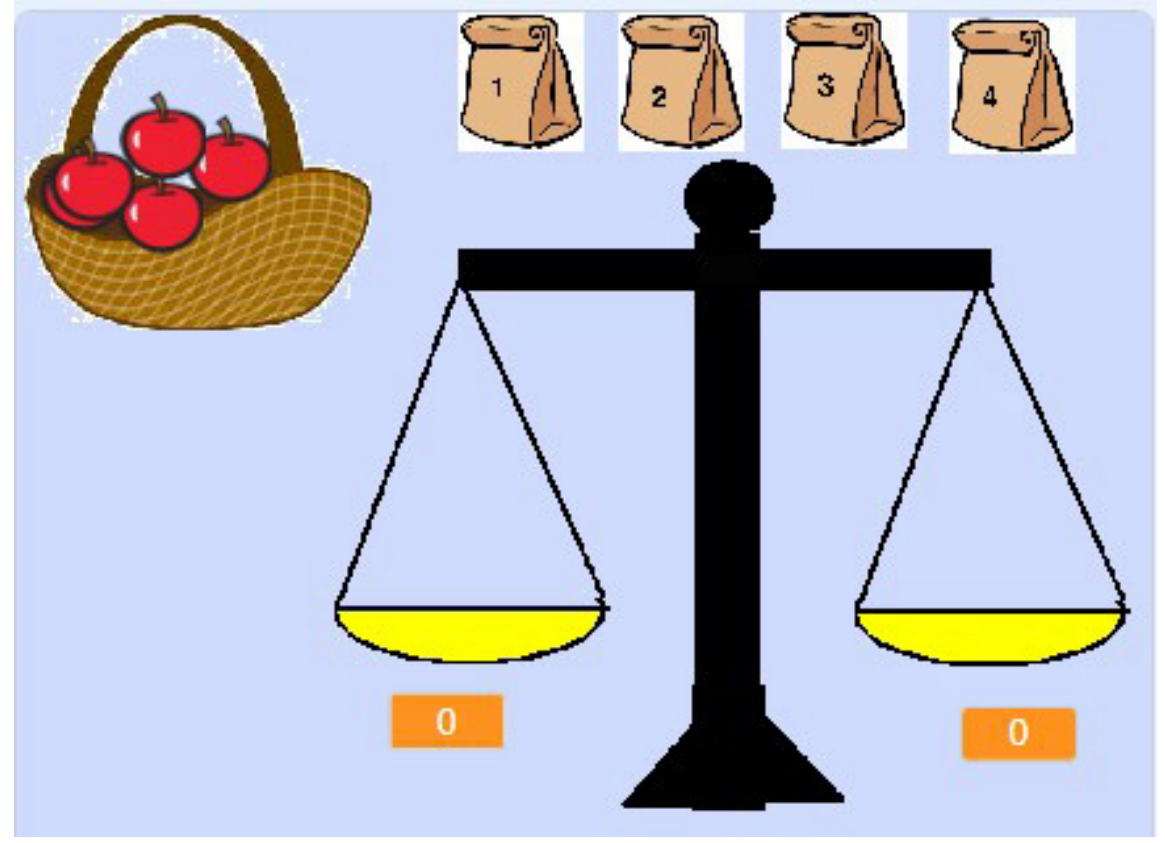

Fonte: Autores (2020). 
Este momento na disciplina teve como objetivo oportunizar aos licenciandos a experimentação e visualização de algumas das habilidades relacionadas ao PC: formulação de problemas, abstração, simulação, generalização, automação, piso baixo e teto alto, modelagem dinâmica, dentre outras. Desta forma, eles puderam explorar na prática como atividades de programação poderiam ser utilizadas para se desenvolver tais habilidades, o que contribuiu também para a compreensão do significado de cada uma delas. Por fim, a discussão sobre cada habilidade relacionada ao PC incluiu também uma busca por relações que poderiam ser estabelecidas entre elas e as competências definidas pela BNCC, buscando-se investigar se e como o PC poderia contribuir para o desenvolvimento destas competências.

Paralelamente às aulas de investigação e fundamentação teórica, os alunos foram orientados à construção do projeto didático, que consistiu no trabalho final desta disciplina. Adotamos o conceito de projeto didático de acordo com Veiga (2012, p. 70), que afirma ser o projeto "uma atividade permeada por intencionalidade na qual o aluno adquire e produz conhecimentos, resolve problemas que o preocupam, autênticos ou simulados da vida real". Trata-se portanto de uma estratégia de ensino, que proporciona uma aprendizagem ativa ao aluno, que possui intencionalidade.

Assim, um projeto postula uma abordagem metodológica diferenciada, em que o aprendiz é o sujeito ativo nesse processo de ensino, juntamente a mediação do professor que pode proporcionar um ambiente desafiador durante o trabalho realizado. Os projetos didáticos são flexíveis e não existe um modelo rígido para organizar seu desenvolvimento, assim sugerimos uma estrutura como possibilidade de trabalho para os discentes, que incluiu: Tema, conteúdos ou habilidades, justificativa, objetivos, recursos, cronograma, produto, metodologia, avaliação e culminância. Estas etapas serão ilustradas no momento em que discutiremos um dos projetos desenvolvidos na seção Resultados e Discussões.

Adotar o projeto didático como instrumento de avaliação permitiu que os futuros professores reunissem numa única atividade o conhecimento teórico e prático assimilado durante a disciplina. Eles precisavam fundamentar suas propostas nas teorias estudadas e assim construir um projeto que reunisse conteúdo (matemática, competências, PC), metodologia de ensino, recursos e critérios de avaliação, propondo a construção de um produto do projeto por seus alunos da Educação Básica. Assim, dariam a oportunidade para seus alunos construírem seus conhecimentos matemáticos enquanto produziam o produto alvo do projeto, ressignificando assim 
a matemática produzida, tornando o processo de aprendizagem significativo e criativo. Como recursos digitais, deveriam fazer uso das tecnologias estudadas durante as aulas: GeoGebra ${ }^{4}$, Scratch e Jclic ${ }^{5}$. Estes softwares deveriam ser incluídos no planejamento de suas aulas como recursos, demonstrando como seriam usados para o cumprimento dos objetivos do projeto.

As atividades desenvolvidas pelos alunos na disciplina, bem como os principais desafios e potencialidades que surgiram são apresentados e discutidos na próxima seção.

\section{Resultados e Discussões}

Nesta seção são apresentados e discutidos os resultados obtidos durante os momentos de formação relatados tendo como base os projetos e atividades desenvolvidas pelos discentes e os relatórios de regência dos licenciandos. Nossa análise pretende discutir o potencial que os projetos e as atividades possuem para articular matemática, PC e competências da BNCC durante os processos de ensino e aprendizagem propostos. Pretendemos também analisar o grau de compreensão expressado pelos licenciandos em matemática, identificando os principais desafios e dificuldades por eles enfrentados. Para tanto, vamos selecionar o trabalho que entendemos ser representativo do conjunto total desenvolvido.

O projeto de ensino tomado das produções da licenciatura foi desenvolvido por três alunas e tinha como objetivo avaliar o impacto do PC quando desenvolvido durante às aulas de matemática junto a uma turma de 7 alunos do $1^{\circ}$ ano do ensino médio com defasagem de aprendizagem. As questões norteadoras relacionadas ao PC e definidas pelas autoras foram: 1) Como garantir o aprendizado sobre equações do $1^{\circ}$ grau e funções do $1^{\circ}$ e $2^{\circ}$ grau para alunos com defasagem, através do pensamento computacional? 2) Há possibilidade de uma real melhora na aprendizagem desses alunos? 3) O pensamento computacional é realmente eficaz? Se sim, por quê? 4) Como desenvolver a capacidade de abstração e generalização em alunos com extrema defasagem de conteúdos?

O tema escolhido pelas alunas foi Minha casa dos sonhos, em que os alunos deveriam produzir uma maquete de sua casa dos sonhos como produto final do projeto. O cronograma previa 4 encontros, num total de 6 aulas de 50 minutos para o desenvolvimento do projeto com os alunos. O conteúdo alvo foi equação e 
função do $1^{\circ}$ grau, e as tecnologias utilizadas foram o GeoGebra e o objeto digital de aprendizagem (ODA) Descubra o valor dos pesos ${ }^{6}$.

A metodologia adotada seguiu as seguintes etapas, descritas no relatório de regência produzido pelas licenciandas:

1. Avaliação diagnóstica, com o objetivo de verificar o nível de conhecimento da turma sobre o conteúdo;

2. Aulas expositivas dialogadas, com momentos de pesquisa, com o objetivo de definir e ilustrar o conceito de uma equação, além de estabelecer uma analogia entre a igualdade de uma equação e o equilíbrio e uma balança.

3. Manipulação do jogo Descubra o valor dos pesos, com o objetivo de discutir e reforçar os conceitos de equação do primeiro grau apresentados nas aulas anteriores.

4. Construção do algoritmo para solução de uma equação do primeiro grau.

5. Proposição e resolução de problemas envolvendo funções do primeiro grau.

6. Pesquisa, discussão e apresentação do conceito de gráficos e funções usando o GeoGebra.

Alguns pontos da metodologia merecem ser discutidos. A segunda etapa contemplou momentos para apresentação e discussão de conceitos de equações do primeiro grau, tendo como base os resultados obtidos na avaliação diagnóstica. Aqui, percebemos que as alunas tiveram o objetivo de apresentar conceitos matemáticos aos alunos fazendo uso de uma metodologia muito próxima da tradicional, em que o professor apresenta o conteúdo já pronto com conceitos já formalizados e sistematizados. Desta forma, percebemos que a concepção pedagógica de projeto didático discutida durante as aulas, em que a aprendizagem dos conceitos acontece de forma processual e durante o desenvolvimento do projeto não foi aplicada. Isto demonstra a dificuldade de se migrar de uma metodologia tradicional para uma metodologia ativa, consequência de uma vivência escolar que privilegia processos tradicionais de ensino e experienciada ao longo de anos pelos estudantes, e que agora na posição de professores tendem a reproduzi-la.

Seguindo esta concepção metodológica, a etapa 3 surge como um momento para reforçar os conteúdos apresentados. No entanto, ao invés de adotarem a tradicional lista de exercícios, fizeram uso do ODA Descubra o valor dos pesos. Por se tratar de um recurso interativo e dinâmico, as experiências interativas dos alunos com o objeto permitiu vivenciar, experimentar as ideias antes apresentadas. Ou seja, um 
conceito que antes havia sido apenas afirmado pelas professoras poderia agora ser comprovado ou negado durante a realização de experimentos, fato este relatado pelas alunas quando da discussão do conceito de igualdade de uma equação. A Figura 3 apresenta uma das telas do objeto digital.

Figura 3 - Objeto Digital de Aprendizagem Descubra o Valor dos Pesos
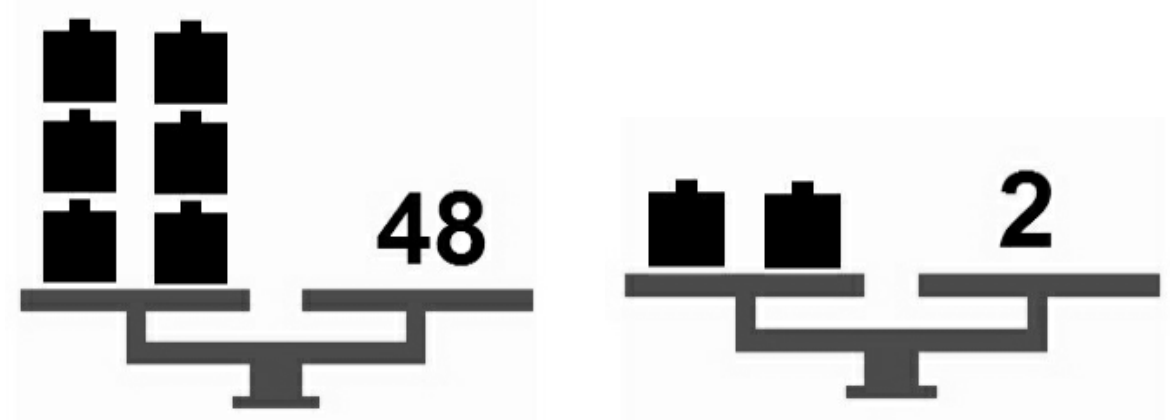

Fonte: Autores (2020).

A etapa 4, que consistiu na construção, compreensão e execução de algoritmos para resolução de equações, também possui diferenças quando comparada a forma tradicional de se desenvolver este conteúdo. Aqui, o ODA foi utilizado para ressignificar o algoritmo tradicional de resolução, proporcionando a compreensão do que significa "somando de um lado, passa para o outro subtraindo", e de acordo com relato das alunas, foi importante pois

Os alunos puderam compreender que omitir a operação inversa em um dos lados da equação é apenas uma estratégia do algoritmo de resolução para poupar tempo. Isto foi importante para a compreensão de que tudo possui um significado, ou seja, a matemática não é impossível e muito menos inventada e cheia de regras sem sentido.

Dando sequência ao projeto, as licenciandas propuseram problemas que envolviam o conceito de funções do primeiro grau, sem antes apresentar esta teoria aos alunos. Os problemas envolviam o cálculo do valor cobrado por um taxista numa corrida de $8 \mathrm{~km}, 17 \mathrm{~km}$ e $24 \mathrm{~km}$, que cobrava $\mathrm{R} \$ 0,70$ por quilômetro rodado e $R \$ 3,50$ de bandeira. Os alunos tentaram descobrir as soluções usando seu conhecimento sobre equações de forma colaborativa e autônoma, com a mediação das professoras, que por fim os questionou sobre uma maneira de se generalizar os resultados obtidos. De acordo com seus relatos 
Este processo exploratório fez com que percebessem que a quilometragem do carro sofria variação, definindo assim um nome para esse valor, no caso o ' $x$ '. Chegaram então a algo como $0,70 x+3,50$, mas ainda sentiam falta de algo para formar uma equação, no caso a igualdade. Inserimos a igualdade e eles pararam para pensar no que viria após o igual. Depois de alguns minutos, concluímos que a conta resultaria no valor a ser pago para o motorista, de modo que os próprios alunos disseram que deveriam dar um nome a este valor. Adotamos a letra P de "pagar", e reescrevendo a função chegamos a $P=0,70 x+3,50$. Fonte: Autores (2020)

Este processo exploratório de resolução de problemas mediado pelas professoras culminou na percepção por parte dos alunos de que naquele momento não existia apenas uma letra, ou variável, mas duas, e que uma dependia da outra. Desta forma, foi-lhes apresentado o conceito de função dentro de um contexto de descoberta. Eles construíram uma função de $\mathrm{P}$, o valor a ser pago, que dependia da quilometragem rodada pelo táxi. Tal vivência foi assim relatada pelas licenciandas

Esta experiência foi interessante porque, diferentemente da aula tradicional, os alunos resolveram um problema antes mesmo de conhecer o conteúdo e acabaram definindo-o no final, ou seja, fizeram o caminho contrário. A balança virtual e as pesquisas realizadas na internet contribuíram muito para desenvolvermos esta metodologia. Fonte: Autores (2020)

A sexta e última etapa envolveu o uso do software GeoGebra para ampliar a aprendizagem sobre função e suas representações gráficas. Os alunos realizaram pesquisas sobre o tema gráficos na internet e construíram um gráfico de barras e de linhas para a função construída na etapa anterior, com o objetivo de permitir a compreensão sobre a utilidade de um gráfico: apresentar visualmente algo representado matematicamente. Além disso, conceitos geométricos foram discutidos e apresentados: eixos cartesianos, ponto, e coordenadas.

O GeoGebra também permitiu a manipulação algébrica das funções construídas para o problema do táxi, os quais perceberam que alterações sobre o valor cobrado por quilometragem impactavam os coeficientes da função e sua representação gráfica. Esta investigação permitiu a compreensão do conceito dos coeficientes e inclinação da reta, a partir dos quais foram desenvolvidos os conceitos de intervalo para o valor cobrado, máximo e mínimo. Além disso, foi possível discutir aspectos relacionados ao contexto real, pois na fala das alunas "não basta colocar qualquer valor nos coeficientes, por exemplo, o taxista não cobraria 200 reais de bandeira ou 50 por quilometro rodado. Isto aproximou a matemática formalizada da realidade do aluno". Fonte: Autores (2020)

Sobre a relação entre matemática, PC e competências, as autoras afirmaram em seu relatório final de regência que durante seus estudos 
contemplamos diversas habilidades relacionadas ao PC, das quais destacamos: formulação de problemas, raciocínio lógico, abstração, construção de algoritmos, modelagem dinâmica, piso baixo e teto alto, paralelismo, simulação e generalização. Além disso, traçamos um paralelo entre estas habilidades e as competências previstas pela Base Nacional Comum Curricular (BNCC), buscando investigar se as habilidades relacionadas ao PC estavam contempladas neste documento e como o PC poderia contribuir para que tais competências pudessem ser desenvolvidas nos alunos. Fonte: Autores (2020).

Deste excerto pode-se concluir que as licenciandas demonstram ter compreendido o objetivo do trabalho proposto na disciplina IEM. A partir de então, decidiram selecionar algumas das habilidades estudadas como alvo de investigação no projeto, as quais acreditam ser de "suma importância para o ensino e aprendizagem de Matemática: raciocínio lógico, capacidade para formular, compreender e resolver problemas, abstração, generalização e construção de algoritmos”. As habilidades elencadas pelas alunas foram investigadas durante o desenvolvimento do projeto, sobre as quais concluíram que conseguiram "trabalhar e estimular o raciocínio lógico nos alunos enquanto formulavam conjecturas e faziam generalizações de ideias. A capacidade de formular e resolver problemas também estimulada durante a elaboração e resolução dos problemas propostos com o auxílio dos softwares,"

\section{Conclusão}

A primeira autora tem ministrado o componente Informática e Educação Matemática desde 2014, buscando introduzir em suas aulas elementos teóricos e práticos que aproximem seus alunos de experiências práticas de regência com o uso das tecnologias digitais. O PC foi introduzido como tópico de estudo no primeiro semestre de 2019. Tal medida se justifica por alguns motivos: a introdução do PC no currículo da Educação Básica é uma tendência em educação; as experiências da primeira autora no ensino de programação a crianças têm apresentado resultados promissores; e, principalmente, o PC foi incluído na BNCC como uma habilidade a ser desenvolvida nos alunos da Educação Básica, relacionado a conteúdos da matemática no Ensino Fundamental. Este último fato, por si só, deve gerar diversas discussões e tomadas de decisão sobre como formar os professores de matemática para essa prática em suas aulas. Acreditamos, portanto que, um dos momentos em que os professores de matemática devem ter contato com o conceito e prática do PC deve ser em sua formação inicial, assim como relatado neste trabalho. 
Dentro do contexto de espaços de formação de professores de matemática, este trabalho procurou discutir algumas questões que emergem a partir da introdução do PC como tópico alvo de ensino e aprendizagem em disciplinas voltadas a formação de professores de matemática: como os professores construirão ambientes de ensino e aprendizagem capazes de articular matemática, competências e PC? Como o PC pode contribuir para o ensino da matemática ao mesmo tempo em que possibilita o desenvolvimento das competências e habilidades previstas na BNCC? Como colocar o PC em prática numa sala de aula com o objetivo de se ensinar e aprender conceitos matemáticos?

Abordar um conceito ainda cercado por dúvidas e imprecisão já é um desafio, que se torna ainda maior quando sua apropriação não depende apenas de procedimentos de memorização ou compreensão de sua definição. Ao contrário, os aprendizes precisam experimentá-lo, praticá-lo através de atividades mão-na-massa que insira os alunos como protagonistas deste processo, para assim desenvolver suas próprias habilidades relacionadas ao PC. Tais vivências proporcionam primeiro o desenvolvimento do $\mathrm{PC}$ nos futuros professores, para posteriormente serem reproduzidas em suas práticas.

Introduzi-lo pela primeira vez apenas no nível superior e esperar que esta experiência (muitas vezes imatura) gere resultados tão complexos quanto os esperados pela BNCC é um grande desafio, o que pôde ser comprovado neste trabalho. Para todos os alunos da turma de 2019 o termo PC era desconhecido. Não apenas sua definição, mas sobretudo as habilidades relacionadas ao PC e sua aplicação na educação. Os licenciandos inclusive desconheciam sua inclusão como um dos objetivos de aprendizagem da BNCC. Na verdade, esta era a situação esperada.

Da experiência relatada a partir do projeto Minha Casa dos Sonhos percebemos que um dos desafios se referia a questões metodológicas relacionadas a compreensão, planejamento e execução de projetos didáticos. Este tema foi alvo leituras, discussões teóricas de alguns autores, e apresentação de seminário, a fim de prepará-los para sua construção. No entanto, a primeira versão elaborada foi refeita por todos os grupos por não terem alcançado os objetivos pretendidos pela metodologia. Isto continuou acontecendo na segunda versão, por exemplo, o projeto relatado previa a construção de uma maquete, mas na prática entregaram um relatório construído pelos alunos. De fato, romper com concepções tradicionais cultivadas há séculos na 
cultura escolar não é um processo simples. Estes modelos tendem a ser reproduzidos pelos futuros professores a partir de suas experiências enquanto alunos.

Outra dificuldade encontrada pelos licenciandos foi com relação a produção dos materiais didáticos digitais usando as tecnologias sugeridas: GeoGebra, Jclic e Scratch. A maioria dos alunos eram inábeis como usuários destas ferramentas, o que dificultou e até mesmo impossibilitou sua inserção como recursos do projeto. Apenas dois grupos conseguiram incluir o Scratch como ferramenta de produção durante os projetos. De acordo com seus relatos, possuíam muita dificuldade de programar no Scratch e se sentiam inseguros em usá-lo junto aos alunos. No entanto, aqueles que enfrentaram tal barreira foram surpreendidos com o desempenho, habilidade e criatividade das crianças em manipular e construir suas ideias no Scratch, afirmando ter sido o momento de maior engajamento dos alunos e satisfação dos professores. No entanto, os grupos que usaram o Scratch para desenvolver seus projetos não conseguiram relacionar a atividade de programação ao pensamento computacional, enfatizando apenas aspectos relacionados ao lúdico a motivação dos alunos para as aulas da matemática.

Após o curso da disciplina esperava-se que os alunos compreendessem o conceito do PC em termos de suas habilidades relacionadas e fossem capazes de aplicá-lo durante o desenvolvimento do projeto elaborado pelos grupos de alunos. No entanto, após a elaboração e apresentação do projeto didático ficou evidente a grande dificuldade dos alunos de articular o ensino do conteúdo às habilidades do PC através de atividades mão-na-massa. Em sua maioria, incluíram apenas os recursos tecnológicos como instrumentos de transmissão de informações ou apresentação e resolução de exercícios. Almejam obter resultados diferentes sem se atentar à metodologia de ensino e aprendizagem adotada.

Todos os grupos tiveram a oportunidade de refazer seus projeto se atentando para as considerações feitas pela professora: definir um tema para o projeto, deixar claro o produto do projeto e definir quais habilidades do PC seriam alvo de investigação. Dos quatro grupos, dois alcançaram resultados satisfatórios na reapresentação. Os outros dois reapresentaram seu projeto sem demostrar compreensão sobre a articulação necessária entre conteúdo, PC e competências. Desta forma, a experiência apontou para mais um desafio: a complexidade de conceber o pensamento computacional como um elemento articulador, como um processo de pensamento que contempla diversos outros processos de pensamento que quando estimulados 
e postos em prática contribuem para o desenvolvimento de diversas habilidades necessárias para a resolução de problemas em diversas áreas do conhecimento. Neste sentido, a dificuldade dos alunos estava em construir projetos didáticos em que alunos agissem como protagonistas no processo de resolução dos problemas e construção do produto, identificando neste processo quais habilidades do PC seriam trabalhas e articuladas às competências da BNCC.

A experiência aqui relatada mostrou que introduzir o PC na BNCC e consequentemente no currículo da Educação Básica gera implicações sobre o planejamento e desenvolvimento dos momentos de formação dos professores. Para se alcançar os resultados esperados, qual seja, um processo de ensino e aprendizagem focado no desenvolvimento de competências e habilidades e do próprio PC, como previsto na legislação, há de se repensar na forma como os futuros professores também vivenciam suas experiências acadêmicas. Submetê-los a um processo de aprendizagem tradicional implicará numa formação tradicional, a qual muito provavelmente será reproduzida pelo futuro professor. Este repensar se torna ainda mais importante quando se concebe uma educação focada no desenvolvimento de habilidades que não podem ser "ensinadas", mas sim estimuladas. Desta forma, os estímulos devem ser iniciados no início da vida escolar dos aprendizes e não postergados para os cursos de nível superior.

Concluímos, portanto, que submeter os futuros professores às novas ideias preconizadas pela BNCC apenas durante uma disciplina de 40 horas em um semestre pode não ser suficiente para garantir que um paradigma tradicional de educação matemática seja rompido. Acreditamos também que os professores formadores de professores precisam tomar ciência dos novos modelos de ensino e aprendizagem pretendidos para então repensar suas práticas nos cursos de formação, buscando proporcionar experiências de aprendizagem ativa, promovendo assim uma vivência não tradicional que poderá ser futuramente reproduzida nas práticas dos futuros professores. 


\section{Mathematics, Computational Thinking and BNCC: challenges and potential of teaching projects and technology in initial teacher education}

\section{Abstract}

This work brings a discussion about computational thinking in mathematics education accompanied by an experience report of the subject Computing and Mathematics Education offered in a undergraduate Math course. This curricular component focused on working with Computational Thinking (CP) linked to the teaching of mathematics through hands-on activities using digital technologies. Such focus arises from the need to update the training of teachers in light of the new guidelines defined by the National Common Curricular Base, which brought Computational Thinking as one of the skills to be developed in K-12 Education students. The objective of this text is, therefore, to discuss the $\mathrm{CP}$ and reflect on the teaching and learning experiences developed during these disciplines, investigating the following problem: what are the potentials and challenges that arise in the spaces dedicated to the initial training of teachers when they propose to work with teaching practices that articulate mathematics, CP and competencies provided for in the National Common Curricular Base (BNCC)? The results obtained point to several possibilities of articulating these three elements while imposing challenges on current and future teachers.

Keywords: K-12 Education; Computational Thinking; Mathematics; Skills; BNCC.

\section{Notas}

1 https://www.sbc.org.br/

2 https://cieb.net.br

3 Ambiente de programação em blocos construído e mantido pelo Massachusetts Institute of Technology (MIT). Acessado através do sítio: scratch.mit.edu

4 Software de Geometria Dinâmica disponível online em https://www.geogebra.org/classic?lang=pt

5 Software de Autoria para a produção de materiais didáticos digitais, disponível para download em https:// clic.xtec.cat/legacy/en/jclic/

6 Objeto Digital de Aprendizagem disponível em https://www.tabuadas.com.br/jogo-dos-pesos/jogo-matematica-pesos-balanca-1.php

\section{Referências}

AHO, A. (2011) Computation and Computational Thinking. Disponível em: <http://ubiquity. acm.org/article.cfm?id=1922682>. Acesso em: 1 junho 2019.

ALMEIDA, M. E. B de. VALENTE, J. A. Pensamento Computacional nas políticas e nas práticas em alguns países. Revista Observatório, Palmas, v. 5, n. 1, p. 202-242, jan-mar. 2019.

BNCC (2018). Base Nacional Comum Curricular: Educação é a Base. Disponível em: <http:// basenacionalcomum. mec.gov.br/images/BNCC_EI_EF_110518_versaofinal_site.pdf>. Acesso em: 1 junho 2019. 
BRASIL (2016). Resolução CNE/CES 5/2016. Diário Oficial da União, Brasília, 17 de novembro de 2016, Seção 1, págs. 22-24 Disponível em: <http://portal.mec.gov.br/index.php?option=com_docman\&view=download\&alias= 52101-rces005-16-pdf\&category_slug=novembro-2016-pdf\&Itemid=30192>. Acesso em: 07 agosto 2018.

CIEB. Currículo de Referência em Tecnologia e Computação: da educação infantil ao ensino fundamental. 2018. Disponível em: <https://curriculo.cieb.net.br/assets/docs/Curriculo_de_Referencia_em_Tecnologia_e_Computacao.pdf>. Acesso em: 10 mar. 2020.

Computing at School, a subdivision of the British Computer Society (BCS). (2015). Computational Thinking: A Guide for Teachers. Disponível em: <http://community.computingatschool. org.uk/files/6695/original.pdf>. Acesso em: 1 junho 2019.

CSTA K12. Computer Science Standards (2016). <https://cdn.ymaws.com/www.csteachers.org/ resource/resmgr/ Docs/Standards/2016StandardsRevision/INTERIM_StandardsFINAL_07222. pdf>. Acesso em: 1 junho 2019.

DENNING P. J. Remaining Trouble Spots with Computational Thinking: Addressing unresolved questions concerning computational thinking. Communications of the ACM, v.60, n. 6, jun 2017.

GADANIDIS, G. Coding as a Trojan Horse for Mathematics Education Reform. Journal of Computers in Mathematics and Science Teaching, v. 34, n. 2, pg. 155-173, 2015.

GADANIDIS, G.; HUGHES, J.M.; MINNITI, L.; WHITE, B.J.G. Computational Thinking, Grade 1 Students and the Binomial Theorem. Digit Exp Math Educ. v.3, pg. 77-96, 2017.

ISTE International Society for Technology in Education. (2016). ISTE Standards for Students, 2016; Disponível em: <http://www.iste. org/standards/standards/for-students-2016>. Acesso em: 1 junho 2019.

MANNILA, L., DAGIENE, V., DEMO, B., GRGURINA, N., MIROLO, C., ROLANDSSON, L.; SETTLE. A. Computational Thinking in K-9 Education. In Proceedings of the Working Group Reports of the 2014 on Innovation \& Technology in Computer Science Education Conference, New York, USA: ACM. p. 1-29, 2014

PAPERT, S. (1980) Mindstorms: Children, computers, and powerful ideas. New York: Basic Books, 1980.

RESNICK, M. Scratch. Massachusets. (2013). Disponível em: <https://scratch.mit.edu/> Acesso em: 31 maio 2019.

RESNICK, M. (2008) Sowing the seeds for a more creative society. Learning \& Leading with Technology. December/January 2007/2008. Disponível em: <https://web.media.mit.edu/ mres/ papers/Learning-Leading-final.pdf>. Acesso em: 11 setembro 2018.

SBC. Diretrizes para ensino de Computação na Educação Básica. 2019. Disponível em: <https:// www.sbc.org.br/ educacao/diretrizes-para-ensino-de-computacao-na-educacao-basica>. Acesso em: 5 julho 2020 .

VEE, A. Understanding computer programming as a literacy. Literacy in Composition Studies, v.1, n. 2, p, 42-64, 2013.

VEIGA, I. P. A. (Org). Projeto de ação didática: Uma técnica de ensino para inovar a sala de aula. $3^{a}$ Ed. Campinas, SP: Papirus, 2012. p. 79-82. 
WING, J. M. Computational thinking and thinking about computing. Philosophical Transactions of the Royal Society, v.366, n.1881, p. 3717-3725, 2008.

WING, J. M. Computational thinking. Communications of the ACM, v. 49, n. 3, p 33-35, 2006.

YADAV, A. C. STEPHENSON, H. HONG. Computational Thinking for Teacher Education. Communications of the ACM, v. 60, n. 4, abr. 2017. 